\title{
Capsule Commentary for Azcarate et al., Medical Reasons for Marijuana Use, Forms of Use, and Patient Perception of Physician Attitudes Among the US Population
}

\author{
Rosanna Smart, PhD and Bryce Pardo, PhD
}

RAND Corporation, Santa Monica, CA, USA.

$\mathrm{J}$ Gen Intern Med 35(7):2252

DOI: $10.1007 / \mathrm{s} 11606-020-05843-\mathrm{w}$

() Society of General Internal Medicine 2020

\begin{abstract}
A $\mathrm{s}$ a growing number of jurisdictions liberalize access to cannabis, healthcare providers will increasingly need to consult with patients about their cannabis use. Given overlapping patterns of cannabis use for medical and recreational purposes, ${ }^{1}$ physicians need to better understand varied reasons and factors for using cannabis to treat symptoms of a particular condition or for other non-medical purposes.
\end{abstract}

Using a nationally representative survey, Azcarate et al. ${ }^{2}$ assess adults' motivations for and perceived physician attitudes toward medical cannabis use. They find a majority of respondents use cannabis medicinally to treat commonly cooccurring conditions of anxiety, insomnia, and chronic pain-findings congruent with surveys of medical cannabis patients $^{3}$ - despite relatively sparse evidence of cannabis' therapeutic value for some of these conditions. ${ }^{4}$ About nine out of ten respondents who informed their doctor reported their physician to be supportive or neutral as to their cannabis use. Since patients may be more willing to divulge their cannabis use if they perceive healthcare providers to be nonjudgmental or supportive, these findings likely overstate physician acceptance about cannabis use generally and specifically about its use in treating a patient's medical condition.

Discussing an individual's cannabis use is an important first step for healthcare providers to assess patient health and establish an appropriate treatment plan. But there are many other factors that providers may need to know — such as route of administration, dosing, cannabinoid profile, and therapeutic effects. Knowing these other dimensions can help physicians shape patient behaviors, encouraging less harmful modes of

Published online April 22, 2020 use, and mitigating problematic consumption patterns. Therefore, it is troubling that nearly half of respondents in Azcarate et al.'s survey either did not have a physician $(21 \%)$ or did not inform their physician about their cannabis use (26\%), with respondents living in a state with legalized medical cannabis more willing to inform their physician. For the former, barriers to medical care may mean cannabis is the only treatment they are receiving. For the latter, stigma surrounding cannabis may preclude the opportunity to engage patients in discussion to fully appreciate potential risks or existing evidence of effectiveness.

Corresponding Author: Rosanna Smart, PhD; RAND Corporation, Santa Monica, CA, USA (e-mail: rsmart@rand.org).

\section{Compliance with Ethical Standards:}

Conflict of Interest: The authors declare that they do not have a conflict of interest.

\section{REFERENCES}

1. Pacula RL, Jacobson M, Maksabedian EJ. In the Weeds: A Baseline View of Cannabis Use Among Legalizing States and Their Neighbours. Addiction 2016 Jun;111(6):973-80.

2. Azcarate PM, Zhang AJ, Keyhani S, Steigerwald S, Ishida JH, Cohen BE. Medical Reasons for Marijuana Use, Forms of Use, and Patient Perception of Physician Attitudes Among the US Population. J Gen Intern Med. https://doi.org/10.1007/s11606-020-05800-7.

3. Kosiba JD, Maisto SA, Joseph W. Patient-reported Use of Medical Cannabis for Pain, Anxiety, and Depression Symptoms: Systematic Review and Meta-analysis. Soc Sci Med. 2019

4. National Academies of Sciences, Engineering, and Medicine. The Health Effects of Cannabis and Cannabinoids: The Current State of Evidence and Recommendations for Research. National Academies Press; 2017 Mar 31.

Publisher's Note: Springer Nature remains neutral with regard to jurisdictional claims in published maps and institutional affiliations. 